\title{
3 Research Square \\ COVID-19 discharged patients in Hunan, China: correlation between early features and prognosis
}

yeyu cai

second xiangya hospital

jiayi liu

second xiangya hospital

Haitao Yang

Ningbo No 2 Hospital

Taili Chen

xiangya hospital

Qizhi Yu

the first hospital of ChangSha

Juan Chen

the central hospital of XiangTan

Deng Huang

Xiangyin county people's hospital

Zhu Chen

second xiangya hospital

Quanliang Shang

second xiangya hospital

Cong Ma

second xiangya hospital

Xiangyu Chen

second xiangya hospital

Enhua Xiao ( $\sim$ xiaoenhua64@csu.edu.cn )

Original research

Keywords: COVID-19, discharged patients, CT features, prognosis

Posted Date: March 20th, 2020

DOI: https://doi.org/10.21203/rs.3.rs-18121/v1

License: (c) (1) This work is licensed under a Creative Commons Attribution 4.0 International License.

Read Full License 
Page $2 / 18$ 


\section{Abstract}

\section{Purpose}

To describe the correlation between the clinical, laboratory and radiological findings with hospitalization days in Coronavirus Infected Disease-19 (COVID-19) discharged patients.

\section{Method}

In this multicenter study, we retrospectively identified 153 discharged patients with COVID-19 pneumonia from Jan 16, 2020 to Feb 26, 2020 in Hunan province. Patients were grouped based on the hospitalization days: Group 1 (hospitalization days $\leqq 12$ days) and Group 2((hospitalization days> 12days). Demographic, clinical characteristics and laboratory findings on admission and the imaging features of the first Chest CT on admission were analyzed. The differences between groups were analyzed using univariate logistic regression to find the impact factors.

\section{Results}

The cohort included 153 discharged patients ( 85 males and 68 females, with the mean age of $42.32 \pm 14.03$ years old). $90(58.8 \%)$ patients had hospitalization days $\leqq 12$ and $63(41.2 \%)$ patients had hospitalization days $>12.44(48.9 \%)$ patients in Group1 and 28(44.4\%) in Group 2 had been to Wuhan. In both Group1 and Group2, most common symptoms at onset were fever $(62.2 \%, 60.3 \%)$ and cough (33.3\%, 50.8\%). Cough was occurred more common in Group 2(50.8\%) than Group 1(33.3\%) with a significant difference ( $p=0.03)$. 6(6.7\%) patients in Group1 and 10(15.9\%) in Group2 had admitting diagnosis as non-pneumonia ( $(\mathrm{m}=0.07)$, some of them occurred mild pneumonia during hospital stay. White blood cell $(2.2 \%, 9.5 \%)$ and neutrophil $(9.5 \%)$ count above normal were more common on in Group $2(p=0.04, p=0.04)$. Patients in Group 2 had higher concentration of aspartate aminotransferase $(P=0.04)$ than Group 1. Most of patients had multiple lesions $(75.6 \%, 69.8 \%)$ with bilateral distribution $(73.3 \%$, $58.7 \%$ ) in both groups. Mixed ground-glass opacity (GGO) and consolidation appearance were seen in most patients. GGO components > consolidation appearance were more common in Group 1(31.1\%) than in Group 2(8.0\%) with a significant difference between groups $(\mathrm{P}<0.01)$. Patients had cough at onset disease (OR, $0.47 ; 95 \% \mathrm{Cl}, 0.23$ to $0.96, \mathrm{p}=0.04)$ and $\mathrm{CT}$ represented as $\mathrm{GGO}$ components more than consolidation ( $\mathrm{OR}, 4.84 ; 95 \% \mathrm{Cl}, 1.80$ to $13.04, \mathrm{p}<0.01)$ were associated with hospitalization days.

\section{Conclusions}

COVID-19 non-pneumonia patients with longer hospitalization days might have the persistent symptoms or pneumonia occurrence after admission. Chest CT could help prompt diagnosis and monitor disease progression, GGO/consolidation $>1$ in mixed lesions was associated with shorter hospitalization days. Special attention should be paid to the role of radiological features in monitoring disease prognosis.

\section{Introduction}


Since several cases of pneumonia from unidentified pathogen have been reported in Wuhan, Hubei province, China in December 2019, an new-type coronavirus infectious pneumonia broke out rapidly, which was designated as a global healthy emergency by World Health Organization $(\mathrm{WHO})^{1}$. This novel coronavirus identified from the throat swab sample by the Chinese Center for Disease Control and Prevention (CDC) was named as COVID-19 by WHO. Thus far, there has been more than 40000 confirmed cases throughout the China and involving more than 25 countries around the wold ${ }^{2}$.

From the recent literatures, most of the patients presented as a lower respiratory tract inflammation including fever, cough, myalgia or fatigue ${ }^{3-5}$. Manifestations are similar to other viral pneumonia such as severe acute respiratory syndrome(SARS) and middle east respiratory syndrome(MERS) ${ }^{6,7}$. CT imaging has been an important role in screening, primary diagnosing and monitoring patients with COVID-19, since lung imaging manifests earlier than clinical manifestations. The imaging findings reported were similar to typical viral pneumonia but with significant features ${ }^{8}$. Some summary articles reported were focused on the clinical and radiology findings and clinical outcomes, the outcomes were designated as severe and non-severe ${ }^{9}$. However, there has no article focused on the prognosis in discharged patients. The purpose of this study was to evaluate whether there is a correlation between the early clinical, laboratory and radiological findings with the different prognosis in discharged patients with COVID-19.

\section{Materials And Methods}

\section{Patients}

We retrospectively identified the discharged patients with laboratory-confirmed COVID-19 from the electronic medical system and picture achieving and communication system (PACS) in two centers in Hunan after Medical Ethical Committee approval (Approved number:2020004). From the Jan 16, 2020 to Feb 26,2020 , there were totally 153 discharged patients ( 85 male and 68 female, with the mean age of $42.32 \pm 14.03$ ) included in this study with following criteria:1) Patients were laboratory-confirmed COVID19 ; 2) Patients were discharged without readmission; 3) Patients underwent chest CT scan and laboratory examination at the initial hospital admission. Patients with severe pneumonia during disease course were excluded. Severe pneumonia was defined as: 1 ) Severe respiratory distress (respiratory rate $>30$ breaths/min); 2) Requirement for oxygen treatment or medical ventilation; 3) SpO2 $<90 \%$. Asymptomatic at the beginning of admission cases and those younger than 14 years old patients were also excluded. The flowchart of patient inclusion and exclusion in this study was summarized in Fig. 1.

The diagnosis of COVID-19 based on the guideline (Trial version 5) from China National Health Commission ${ }^{10}$ was as follows: 1) Suspected patients with detection of COVID-19 by real-time reversetranscription-polymerase chain reaction (RT-PCR); 2) Suspected patients with virus gene sequence from respiratory tract of blood sample which highly match with COVID-19. Discharge criteria based on the guideline (Trial version 5) includes: 1) Temperature returned to normal for more than 3 days and respiratory symptoms relieve significantly; 2) Chest radiologic images demonstrated significant 
improvement; 3 ) Negative nucleic acid test for two consecutive respiratory pathogens (sampling interval $\geq 1$ day).

Based on the hospitalization days, we designated two groups patients in our study: group 1 (hospitalization days $\leq 12$ days) and group 2 (hospitalization days $>12$ days).

\section{Data collection}

Demographic and clinical characteristics, laboratory findings data were reviewed from electronic medical records by two trained physicians. Demographic information included sex, age, exposure history, smoking history and underlying comorbidities. Clinical characteristics included the onset temperature and symptoms, the highest temperature and symptoms during hospital stay and the diagnosis on admission.

\section{CT image acquisition}

CT scans were obtained using one of the following scanner: GE, HiSpeed-Dual, 64-slice LightSpeed VCT (GE Medical Systems), SOMATOM Emotion and SOMATOM Definition AS (Siemens Healthineers, Forchheim, Germany). Scans were done from the level of the upper thoracic inlet to the inferior level of the costophrenic angle with parameters as follows: tube voltage $120 \mathrm{kVp}$; tube current was regulated by an automatic exposure control system (CARE Dose 4D; Siemens Healthineers); pitch, 0.75-1.5. Images were reconstructed with a slice thickness of $1 \mathrm{~mm}$ or $5 \mathrm{~mm}$ and an interval of $1 \mathrm{~mm}$ or $5 \mathrm{~mm}$, respectively.

\section{Image interpretation}

All Digital Imaging and Communications in Medicine (DICOM) images from cases were analyzed blindly and independently by three radiologists (5-year, 15-year and 20-year experience in interpreting chest CT images). Axial CT images and other multiplanar reconstructions in both lung window (width, $1500 \mathrm{HU}$; level, - $700 \mathrm{HU}$ ) and mediastinal window (width, $350 \mathrm{HU}$; level, $40 \mathrm{HU}$ ) were reviewed. For each patient, features including number of lesion (single or multiple), number of lobes involved (ranging from 0-5), lesion density (pure ground-glass opacity[GGO], pure consolidation and mixed GGO and consolidation), lesion morphology (presence of nodule, patchy shadowing and linear shadowing), lesion distribution (bilateral or unilateral) and presence of bronchial abnormality (including air bronchogram sign and bronchodilation) were analyzed. A semi-quantitative CT score system was used to assess the involvement degree in each lung lobe: no involvement correspond to a score of $0,1 \%-25 \%$ involvement to a sore of $1,25 \%-50 \%$ score of $2,50 \%-75 \%$ score of 3 and more than $75 \%$ to a score of $4^{11}$. For patients with mixed GGO and consolidation lesions, we defined them into two scenarios, GGO/consolidation > 1 referred to patients with GGO predominantly, and GGO/consolidation < 1 referred to consolidation predominantly, evaluated by three radiologists. After separate evaluation from each radiologist, the disagreements were discussed to made consensus.

\section{Statistical Analysis}


Continuous variables were expressed as the means and standard deviations (SD), and categorical variables were expressed as the counts and percentages in each category. We grouped patients into hospitalization days $\leqq 12$ days and $>12$ days. Wilcoxon rank-sum tests were applied to the continuous variables, chi-square tests and Fisher's exact tests were used for categorical variables as appropriate. Pvalues $<0.05$ was considered as statistically significant. All the variables which have statistically significant difference between two groups were analyzed using logistic regression to find the independent influential factors. All statistical analysis was performed using SPSS(IBM).

\section{Results}

\section{Demographic and Clinical Characteristics}

Among all 153 discharged patients with confirmed COVID-19, the average hospitalization days were $12.34 \pm 4.39$ (range from 4 to 25 ) with the median number of 12 days. The time from onset to admission, time during hospitalization and the time from onset to discharge of all patients were demonstrated in Fig. 2. We divided 153 patients into two groups based on their hospitalization days. 90(58.8\%) patients who had hospital stay no more than 12 days were assigned to group 1.63 patients (41.2\%) who had longer hospitalization days (more than 12 days) were assigned to group 2. The demographic and clinical characteristics of the patients by group are summarized in the Table 1. In the full cohort, there are $85(55.6 \%)$ male and $68(44.4 \%)$ female with the mean age of 42.3 years (SD 14.0). There was no statistically significant difference in age $(p=0.08)$ or gender $(p=0.43)$ or current smoking history $(p=$ 0.52 ) between groups. A history of direct exposure to Wuhan was documented in $47.1 \%$. Other $52.9 \%$ patients had contact with people from Wuhan, and there was no significant difference between two groups $(P=0.29)$. There were $6(6.7 \%)$ patients in Group1 and $10(15.9 \%)$ in Group2 had admitting diagnosis as non-pneumonia $(p=0.07)$. Some non-pneumonia patients have longer hospitalization days due to the persistent symptoms or pneumonia occurrence during admission. Their CT images were normal at first but occurred abnormalities during admission (Fig. 3). The most common symptoms at onset and during admission were fever (94,61.4\%; 92, 60.1\%) and cough $(62,40.5 \% ; 93,60.8 \%)$ respectively. No significant difference in clinical symptoms were found between two groups. The mean temperature at onset and the highest temperature during admission were $38.43 \pm 0.46$ and $37.38 \pm 3.06$ respectively with no statistically significant difference. 
Table 1

Demographic and clinical characteristics of patients in this study

\begin{tabular}{|c|c|c|c|c|}
\hline & $\begin{array}{l}\text { All patients } \\
(n=153)\end{array}$ & $\begin{array}{l}\text { Group } 1 \\
\text { (hospitalization } \\
\text { days } \leq 12) \\
(n=90)\end{array}$ & $\begin{array}{l}\text { Group } 2 \\
\text { (hospitalization } \\
\text { days }>12) \\
(n=63)\end{array}$ & $\begin{array}{l}\mathrm{P} \\
\text { value }\end{array}$ \\
\hline Age & $\begin{array}{l}42.32 \pm \\
14.03\end{array}$ & $39.92 \pm 13.71$ & $44.00 \pm 13.40$ & 0.08 \\
\hline Gender & & & & 0.43 \\
\hline Male & $85(55.6 \%)$ & $52(57.8 \%)$ & $33(52.4 \%)$ & \\
\hline Female & $68(44.4 \%)$ & $38(42.2 \%)$ & $30(47.6 \%)$ & \\
\hline History of exposure to Wuhan & & & & 0.29 \\
\hline Direct & 72(47.1\%) & $44(48.9 \%)$ & $28(44.4 \%)$ & \\
\hline Indirect & $81(52.9 \%)$ & $46(51.1 \%)$ & $35(55.6 \%)$ & \\
\hline Current smokers & $18(11.8 \%)$ & $12(13.3 \%)$ & $6(9.5 \%)$ & 0.52 \\
\hline \multicolumn{5}{|l|}{ Comorbidities } \\
\hline Hypertension & $24(15.7 \%)$ & $11(12.2 \%)$ & $13(20.6 \%)$ & 0.16 \\
\hline Diabetes & $13(8.5 \%)$ & $6(6.7 \%)$ & $7(11.1 \%)$ & 0.33 \\
\hline Coronary heart disease & $3(2.0 \%)$ & $1(1.1 \%)$ & $2(3.2 \%)$ & 0.37 \\
\hline Cerebrovascular diseases & $4(2.6 \%)$ & $1(1.1 \%)$ & $3(4.8 \%)$ & 0.16 \\
\hline Cancers* & $1(0.7 \%)$ & $1(1.1 \%)$ & $0(0 \%)$ & 1.00 \\
\hline More than one comorbidity & $48(31.4 \%)$ & $26(28.9 \%)$ & $22(34.9 \%)$ & 0.43 \\
\hline Onset temperature & $\begin{array}{l}38.43 \pm \\
0.46\end{array}$ & $38.25 \pm 0.36$ & $38.53 \pm 0.49$ & 0.21 \\
\hline \multicolumn{5}{|l|}{ Onset symptoms } \\
\hline Fever & $94(61.4 \%)$ & $56(62.2 \%)$ & $38(60.3 \%)$ & 0.81 \\
\hline Cough & $62(40.5 \%)$ & $30(33.3 \%)$ & $32(50.8 \%)$ & 0.03 \\
\hline Shortness of breath & $8(5.2 \%)$ & $3(3.3 \%)$ & $5(7.9 \%)$ & 0.21 \\
\hline
\end{tabular}

Data are presented as medians \pm SD and $\mathrm{n}(\%)$.

*Cancers referred to any malignancy. All cases were stable disease .P values denoted the comparison between Group 1 and Group 2. 


\begin{tabular}{|c|c|c|c|c|}
\hline & $\begin{array}{l}\text { All patients } \\
(n=153)\end{array}$ & $\begin{array}{l}\text { Group } 1 \\
\text { (hospitalization } \\
\text { days } \leq 12) \\
(n=90)\end{array}$ & $\begin{array}{l}\text { Group } 2 \\
\text { (hospitalization } \\
\text { days }>12) \\
(n=63)\end{array}$ & $\begin{array}{l}\mathrm{P} \\
\text { value }\end{array}$ \\
\hline More than one symptom & $73(47.7 \%)$ & $38(42.2 \%)$ & $35(55.6 \%)$ & 0.10 \\
\hline Diagnosis on admission & & & & 0.07 \\
\hline Simple infection & $16(10.5 \%)$ & $6(6.7 \%)$ & $10(15.9 \%)$ & \\
\hline Mild pneumonia & 137(89.5\%) & $84(93.3 \%)$ & $53(84.1 \%)$ & \\
\hline \multicolumn{5}{|l|}{ Symptoms on admission } \\
\hline Fever & $92(60.1 \%)$ & $49(54.4 \%)$ & $43(68.3 \%)$ & 0.86 \\
\hline Cough & $93(60.8 \%)$ & $50(55.6 \%)$ & $43(68.3 \%)$ & 0.11 \\
\hline Shortness of breath & $18(11.8 \%)$ & $9(10.0 \%)$ & $9(14.3 \%)$ & 0.42 \\
\hline More than one symptom & $78(51.0 \%)$ & $43(47.8 \%)$ & $35(55.6 \%)$ & 0.34 \\
\hline $\begin{array}{l}\text { Highest temperature on } \\
\text { admission }\end{array}$ & $\begin{array}{l}37.38 \pm \\
3.06\end{array}$ & $37.02 \pm 3.88$ & $37.91 \pm 0.76$ & 0.07 \\
\hline $\begin{array}{l}\text { Days from symptom onset to } \\
\text { admission }\end{array}$ & $6.07 \pm 4.43$ & $6.79 \pm 4.67$ & $5.03 \pm 3.89$ & 0.02 \\
\hline \multicolumn{5}{|c|}{ Data are presented as medians \pm SD and $n(\%)$. } \\
\hline
\end{tabular}

\section{Laboratory and Radiologic findings}

Table 2 shows the laboratory and radiologic findings by groups at the initial admission. 
Table 2

Laboratory and radiological findings of patients in this study.

\begin{tabular}{|c|c|c|c|}
\hline & $\begin{array}{l}\text { Days }(\leq 12) \text { from admission to } \\
\text { discharge }(n=90)\end{array}$ & $\begin{array}{l}\text { Days }(>12) \text { from admission to } \\
\text { discharge }(n=63)\end{array}$ & $\begin{array}{l}\mathrm{p} \\
\text { value }\end{array}$ \\
\hline \multicolumn{4}{|l|}{ Laboratory findings } \\
\hline $\begin{array}{l}\text { White blood cell count, } \\
>10^{*} 10 \nabla / \mathrm{L}\end{array}$ & $2(2.2 \%)$ & $6(9.5 \%)$ & 0.04 \\
\hline $\begin{array}{l}\text { White blood cell count, } \\
<4^{*} 10 \otimes / L\end{array}$ & $31(34.4)$ & $18(28.6 \%)$ & 0.44 \\
\hline $\begin{array}{l}\text { Neutrophil count, }>7 \star \\
10 \rrbracket / L\end{array}$ & $2(2.2 \%)$ & $6(9.5 \%)$ & 0.04 \\
\hline $\begin{array}{l}\text { Lymphocyte count, < } \\
0.8^{\star} 10 \otimes / L\end{array}$ & $18(20 \%)$ & 10(15.9\%) & 0.52 \\
\hline $\begin{array}{l}\text { Total bilirubin, > } \\
21 \mathrm{mmol} / \mathrm{L}\end{array}$ & $5(5.6 \%)$ & $9(14.8 \%)$ & 0.06 \\
\hline Albumin, $<35 \mathrm{~g} / \mathrm{L}$ & $20(22.2 \%)$ & $9(14.3 \%)$ & 0.22 \\
\hline $\begin{array}{l}\text { Alanine } \\
\text { aminotransferase, > } \\
40 U / L\end{array}$ & $6(6.7 \%)$ & 11(17.5\%) & 0.04 \\
\hline $\begin{array}{l}\text { Aspartate } \\
\text { aminotransferase, > } \\
40 U / L\end{array}$ & $9(10.0 \%)$ & $7(11.1 \%)$ & 0.82 \\
\hline $\begin{array}{l}\text { Lactate } \\
\text { dehydrogenase, > } \\
225 \mathrm{U} / \mathrm{L}\end{array}$ & 17(18.9\%) & $16(25.4 \%)$ & 0.34 \\
\hline $\begin{array}{l}\text { Procalcitonin, > } \\
0.05 \mathrm{ng} / \mathrm{mL}\end{array}$ & $18(20.0 \%)$ & $15(23.8 \%)$ & 0.57 \\
\hline $\begin{array}{l}\text { Blood urea nitrogen, > } \\
8.2 \mathrm{mmol} / \mathrm{L}\end{array}$ & $2(2.2 \%)$ & $3(4.8 \%)$ & 0.39 \\
\hline $\begin{array}{l}\text { Creatinine, > } \\
\text { 104umol/L }\end{array}$ & $3(3.3 \%)$ & $1(1.6 \%)$ & 0.51 \\
\hline $\begin{array}{l}\text { Creatinine kinase, > } \\
200 U / L\end{array}$ & $4(4.4 \%)$ & $7(11.1 \%)$ & 0.12 \\
\hline D-dimer, > $1 \mathrm{mg} / \mathrm{L}$ & $9(10.0 \%)$ & $5(7.9 \%)$ & 0.67 \\
\hline
\end{tabular}

Data are presented as $\mathrm{n}(\%)$.

P values denoted the comparison between group1 and group2 


$\begin{array}{lll}\text { Days }(\leq 12) \text { from admission to } & \text { Days }(>12) \text { from admission to } \\ \text { discharge }(n=90) & p \\ \text { discharge }(n=63) & \text { value }\end{array}$

Number of lesions, $\mathrm{n}$

\begin{tabular}{|c|c|c|c|}
\hline Single & $16(17.8 \%)$ & $9(14.3 \%)$ & 0.20 \\
\hline Multiple & $68(75.6 \%)$ & $44(69.8 \%)$ & 0.43 \\
\hline $\begin{array}{l}\text { Average number of } \\
\text { lobes involved, } n\end{array}$ & $2.98 \pm 1.45$ & $2.94 \pm 1.56$ & 0.91 \\
\hline CT score, $\mathrm{n}$ & $4.28 \pm 2.78$ & $4.44 \pm 3.11$ & 0.80 \\
\hline \multicolumn{4}{|l|}{ Density, n } \\
\hline $\begin{array}{l}\text { Pure ground-glass } \\
\text { opacity }\end{array}$ & $2(2.2 \%)$ & $5(7.9 \%)$ & 0.10 \\
\hline Pure consolidation & $10(11.1 \%)$ & $8(12.7 \%)$ & 0.76 \\
\hline GGO/consolidation $>1$ & $28(31.1 \%)$ & $5(8.0 \%)$ & $\begin{array}{l}< \\
0.01\end{array}$ \\
\hline GGO/consolidation $<1$ & $44(48.9 \%)$ & $35(55.6 \%)$ & 0.42 \\
\hline \multicolumn{4}{|l|}{ Morphology, n } \\
\hline Nodule & $23(25.6 \%)$ & $16(25.4 \%)$ & 0.98 \\
\hline Patchy shadowing & $40(44.4 \%)$ & $24(38.1 \%)$ & 0.43 \\
\hline Lineal shadowing & $21(23.3 \%)$ & $13(20.6 \%)$ & 0.69 \\
\hline \multicolumn{4}{|l|}{ Distribution, $\mathrm{n}$} \\
\hline Unilateral & $18(20.0 \%)$ & $16(28.6 \%)$ & 0.43 \\
\hline Bilateral & $66(73.3 \%)$ & $37(58.7 \%)$ & 0.06 \\
\hline \multicolumn{4}{|l|}{ Bronchus, n } \\
\hline Air Bronchogram sign & $57(63.3 \%)$ & $32(50.8 \%)$ & 0.12 \\
\hline Bronchodilation & $27(30.0 \%)$ & $21(33.3 \%)$ & 0.66 \\
\hline $\begin{array}{l}\text { No abnormal findings, } \\
\mathrm{n}\end{array}$ & $6(6.7 \%)$ & $10(15.9 \%)$ & 0.07 \\
\hline
\end{tabular}

Data are presented as $\mathrm{n}(\%)$.

$\mathrm{P}$ values denoted the comparison between group1 and group2

White blood cell $(P=0.04)$ and neutrophil $(P=0.04)$ count above normal were more common in Group 2 $(6,9.5 \% ; 6,9.5 \%)$ than in Group 1(2, 2.2\%; 2, 2.2\%). Patients in Group 2(11, 17.5\%) had higher 
concentration of aspartate aminotransferase $(P=0.04)$ than in Group 1(6. 6.7\%). Other laboratory findings didn't significantly differ between groups. Except 6(6.7\%) patients in Group1 and 10(15.9\%) in Group 2 without abnormal finding in Chest CT at the initial on admission, other patients had abnormal CT imaging features (Table 2). Most of patients had multiple lesions $(75.6 \%, 69.8 \%)$ with bilateral distribution (73.3\%, 58.7\%) in both Group 1 and Group 2. The mean number of lobes involved in Group 1 was $2.98 \pm 1.45$ and $2.94 \pm 1.56$ in Group 2 with no significant difference $(P=0.91)$. The mean score of the lung involvement had no significant difference between Group1 (4.28 \pm 2.78$)$ and Group 2(4.44 \pm 3.11 , $P=0.80$ ). Most of the patients $C T$ images represented as mixed density (including ground-glass opacity and consolidation) in both groups, but the proportion of GGO and consolidation of each patients was different. The demonstration of GGO components more than consolidation (Fig. 4.) was higher in Group $1(28,31.1 \%)$ than in Group $2(5,8.0 \%)$ with a significant difference between groups $(p<0.01)$. The demonstration of consolidation components more than GGO (Fig. 5.) was higher in Group 2(35, 55.6\%) than in Group 1(44,48.9\%), however there is no significant difference between two groups $(p=0.42)$. The morphology features, includes the presence of nodular $(p=0.98)$, patchy shadowing $(p=0.43)$ and linear shadowing $(p=0.63)$ were no significant difference between Group1 and Group 2. Neither in the presence of air bronchogram sign $(p=0.12)$ and bronchodilation $(p=0.66)$.

\section{Clinical characteristic, laboratory findings, radiological findings and prognosis}

Five variables from clinical characteristics, laboratory findings and radiological findings that were significant difference between two groups were analyzed using univariate logistic regression. The results were summarized in Table 3. Patients had cough at onset disease (OR, 0.47; 95\% $\mathrm{Cl}, 0.23$ to $0.96, \mathrm{p}=$ 0.04), CT represented as $\mathrm{GGO}$ components more than consolidation ( $\mathrm{OR}, 4.84 ; 95 \% \mathrm{Cl}, 1.80$ to $13.04, \mathrm{p}<$ 0.01 ) were associated with hospitalization days.

Table 3

Univariate logistic regression analysis of risk factors and patients' hospitalization days

\begin{tabular}{|llll|}
\hline Factors & OR & $95 \% \mathrm{Cl}$ & P value \\
\hline Cough onset & 0.47 & $0.23-0.96$ & 0.04 \\
\hline White blood cell count, $>10 * 10 \varangle / \mathrm{L}$ & 0.61 & $0.03-13.53$ & 0.75 \\
\hline Neutrophil count, $>7 * 10 \rrbracket / \mathrm{L}$ & 0.28 & $0.01-6.43$ & 0.43 \\
\hline Alanine aminotransferase, $>40 \mathrm{U} / \mathrm{L}$ & 0.52 & $0.17-1.63$ & 0.26 \\
\hline Lesions with GGO/consolidation $>1$ & 4.84 & $1.80-13.04$ & $<0.01$ \\
\hline
\end{tabular}

\section{Discussion}


COVID-19 as an emerging infectious disease has aroused more and more attention since December 2019. Although the mortality rate of COVID19 is considerably lower than that of SARS in 2003 and MERS in 2012 , COVID-19 is highly infectious and could be a persistent health threat. Recently, a epidemiologic study from 44672 laboratory-confirmed COVID-19 patients showed that most cases (81\%) were classified as mild type which included non-pneumonia and mild pneumonia ${ }^{3}$. Therefore, summarizing the characteristics of mild cases would be important and helpful to improve the understanding of COVID-19.

We retrospectively observed a group of 153 discharged patients with laboratory-confirmed COVID-19 mild pneumonia in order to determine the correlation between clinical features and pneumonia prognosis. All patients had complete medical records including clinical information, laboratory and radiological data required for this study, and explicit inclusion and exclusion criteria for each patient were used to confirm the representative population. In our study, average hospitalization days of discharged patients were $12.34 \pm 4.39$ (range,4-25) days, and median was 12 days. In addition, very little was found in the previous literature on the question about how to divide into groups based on the hospitalization days in viral pneumonia. Thus, we used 12 days as a cut-off value to divide the discharged patients into two groups.

Fever (61.4\%) and cough (40.5\%) were the most common symptoms at onset in patients with COVID19 mild pneumonia. In addition, the number of patients who had cough as the onset symptom showed a significant difference between two groups. However, the previous study did not report the correlation between symptom at onset and hospitalization days ${ }^{12}$. This finding might be due to the differences in small cohorts or demographic characteristics. Further study would be beneficial to reveal the possible reasons. Surprisingly, the number of non-pneumonia patients has no significant difference in two groups with different hospitalization days. That is to say, few non-pneumonia patients also have longer hospitalization days than that of mild pneumonia patients. In our cohort, the preliminary diagnoses of 10 patients who had more than 12 hospitalization days were non-pneumonia. These patients experienced multiple CT scans during hospitalization and only 2 of them were finally diagnosed as mild pneumonia due to the positive CT findings. Overall, a small part of non-pneumonia patients might have longer hospitalization days due to the persistent symptoms or pneumonia occurrence after admission.

The mean number of involved lung lobes was 2.9 and CT score was 4.3, with non-specific features such as number of lesions, morphology, distribution and bronchus involved in our cohort. These findings are similar to those of previous radiological studies of patients with COVID-19 mild pneumonia ${ }^{13}$. However, compared with the early characteristics of lesions which had the majority of pure ground-glass opacity ${ }^{14}$, the characteristics of patients in our cohort showed the majority of mixed lesions. In order to investigate the possible reasons for the discrepancies in mixed lesions, we calculated the mean admission time and the proportion of ground-glass opacity and consolidation, respectively. These results showed that the mean admission time had no difference between the two group patients, and the greater proportion of ground-glass opacity had an obvious difference between the two group patients. Further investigation using binary logistic regression also revealed that the greater proportion of ground-glass opacity was associated with the hospitalization days.

Page 12/18 
There were some limitations in our study. Firstly, as a relatively small and three-center study, it is so difficult to avoid selection bias, and characteristics of enrolled patients may not be representative. Secondly, due to the average age of the patients in our cohort was around 40 years old, whether these results are generalizable to COVID-19 mild pneumonia patients in children or aged greater than 70 years old needs further evaluation. Finally, as lung biopsy specimens were unable to analysis in this study, the relationship between histopathological and radiological findings remains to be investigated.

\section{Conclusions}

In conclusion, this was a retrospective, multicenter, and comprehensive study focused on the impact factors in hospitalized COVID-19 mild pneumonia outcomes. COVID-19 non-pneumonia patients with longer hospitalization days might have the persistent symptoms or pneumonia occurrence after admission. Chest CT could help prompt diagnosis and monitor disease progression, GGO/consolidation $>1$ in mixed lesions was associated with shorter hospitalization days. Special attention should be paid to the role of radiological features in monitoring disease prognosis.

\section{Declarations}

\section{Ethics approval and consent to participate:}

This study was approved by our Medical Ethical Committee (approval number: 2020004). The requirement for informed consent was waived given the retrospective nature of this study, as per CIOMS guidelines.

Funding: none

Availability of data and material: yes

Conflicts of interest/Competing interest: The authors report no conflict of interest

\section{Authors' contributions}

Conceptualization: Enhua Xiao; Data curation: Haitao Yang, Deng Huang and Qizhi Yu; Formal analysis: Mian Wang and Qingping Guo; Investigation: Enhua Xiao; Methodology: Zhu Chen, Quan-Liang Shang and Cong Ma; Project administration: Enhua Xiao; Resources: Qizhi Yu and Enhua Xiao; Supervision: Taili Chen; Validation: Qizhi Yu; Writing - original draft: Yeiyu Cai and Jiayi Liu; Writing - review \& editing, Yeiyu Cai and Jiayi Liu.

\section{Acknowledgements}

We would like to convey our greatest respect to the fighters who are fighting COVID-19.

\section{Consent for publication}




\section{References}

1. Lei J, Li J, Li X, Qi X. CT Imaging of the 2019 Novel Coronavirus (2019-nCoV) Pneumonia. Radiology. 2020:200236.

2. World Health O. Novel Coronavirus (2019-nCoV): situation report, 21. 2020; https://apps.who.int/iris/handle/10665/330990.

3. Chen N, Zhou M, Dong X, Qu J, Gong F, Han Y, et al. Epidemiological and clinical characteristics of 99 cases of 2019 novel coronavirus pneumonia in Wuhan, China: a descriptive study. The Lancet. 2020;395(10223):507-513.

4. Kanne JP. Chest CT Findings in 2019 Novel Coronavirus (2019-nCoV) Infections from Wuhan, China: Key Points for the Radiologist. Radiology. 2020.

5. Huang C, Wang Y, Li X, Ren L, Zhao J, Hu Y, et al. Clinical features of patients infected with 2019 novel coronavirus in Wuhan, China. The Lancet. 2020;395(10223):497-506.

6. Tsang KW, Ho PL, Ooi GC, Yee WK, Wang T, Chan-Yeung M, et al. A Cluster of Cases of Severe Acute Respiratory Syndrome in Hong Kong. New England Journal of Medicine. 2003;348(20):1977-1985.

7. Assiri A, Al-Tawfiq JA, Al-Rabeeah AA, Al-Rabiah FA, Al-Hajjar S, Al-Barrak A, et al. Epidemiological, demographic, and clinical characteristics of 47 cases of Middle East respiratory syndrome coronavirus disease from Saudi Arabia: a descriptive study. The Lancet Infectious Diseases. 2013;13(9):752-761.

8. Pan Y, Guan H, Zhou S, Wang Y, Li Q, Zhu T, et al. Initial CT findings and temporal changes in patients with the novel coronavirus pneumonia (2019-nCoV): a study of 63 patients in Wuhan, China. Eur Radiol. 2020.

9. $C H, Y W, X L, L R, J Z, Y H$, et al. Clinical features of patients infected with 2019 novel coronavirus in Wuhan, China. Lancet (London, England). 2020.

10. Diagnosis and treatment of pneumonitis caused by new coronavirus (trial version 5). China National Health Commission: China National Health Commission;2020.

11. Chung M, Bernheim A, Mei X, Zhang N, Huang M, Zeng X, et al. CT Imaging Features of 2019 Novel Coronavirus (2019-nCoV). Radiology. 2020.

12. D W, B H, C H, F Z, X L, J Z, et al. Clinical Characteristics of 138 Hospitalized Patients With 2019 Novel Coronavirus-Infected Pneumonia in Wuhan, China. JAMA. 2020.

13. F P, T Y, P S, S G, B L, L L, et al. Time Course of Lung Changes On Chest CT During Recovery From 2019 Novel Coronavirus (COVID-19) Pneumonia. Radiology. 2020:200370.

14. Shi H, Han X, Jiang N, Cao Y, Alwalid O, Gu J, et al. Radiological findings from 81 patients with COVID-19 pneumonia in Wuhan, China: a descriptive study. The Lancet Infectious Diseases. 2020.

\section{Figures}




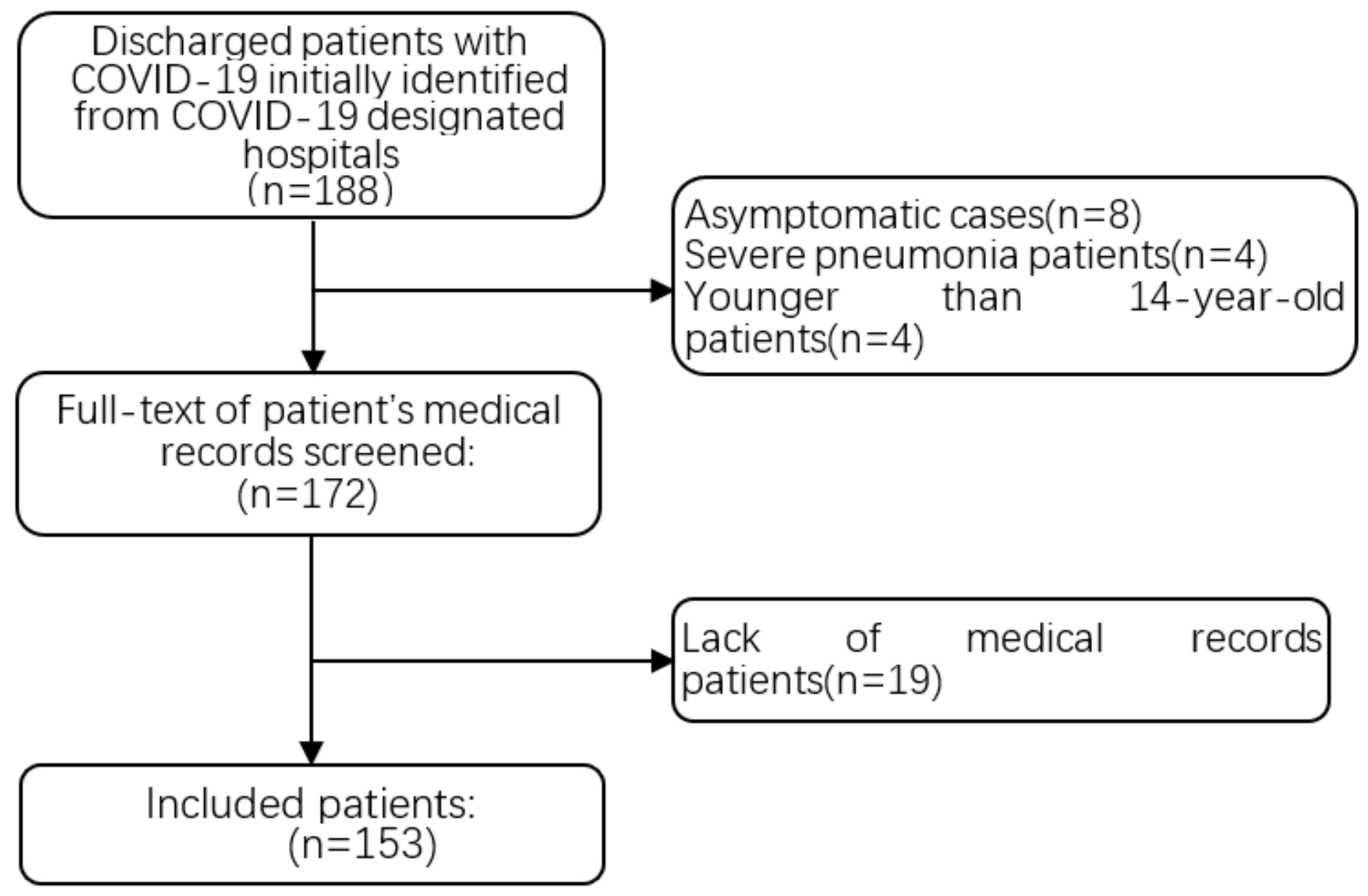

Figure 1

Flowchart of patient inclusion and exclusion in this study
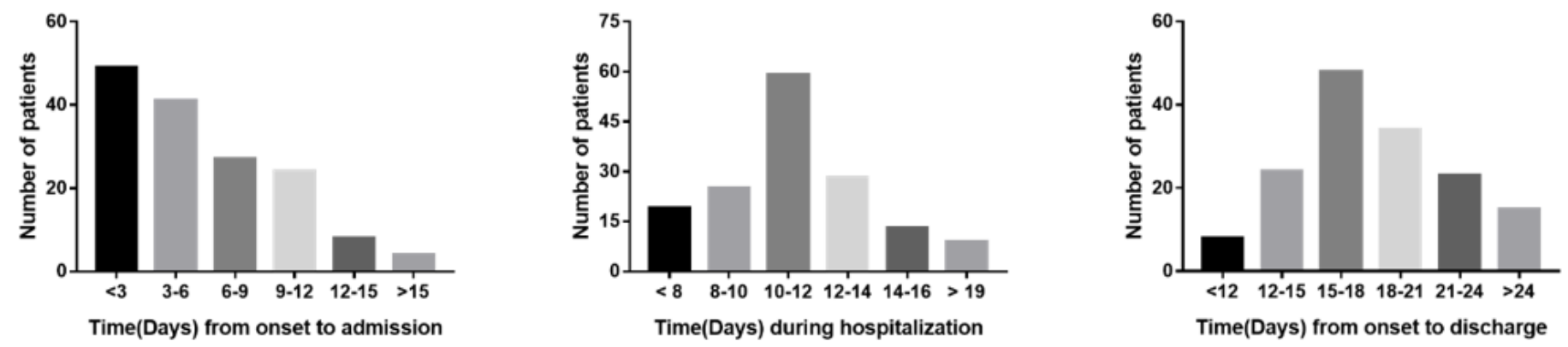

Figure 2

Hospitalization day and other time distributions for COVID-19 infected patients 


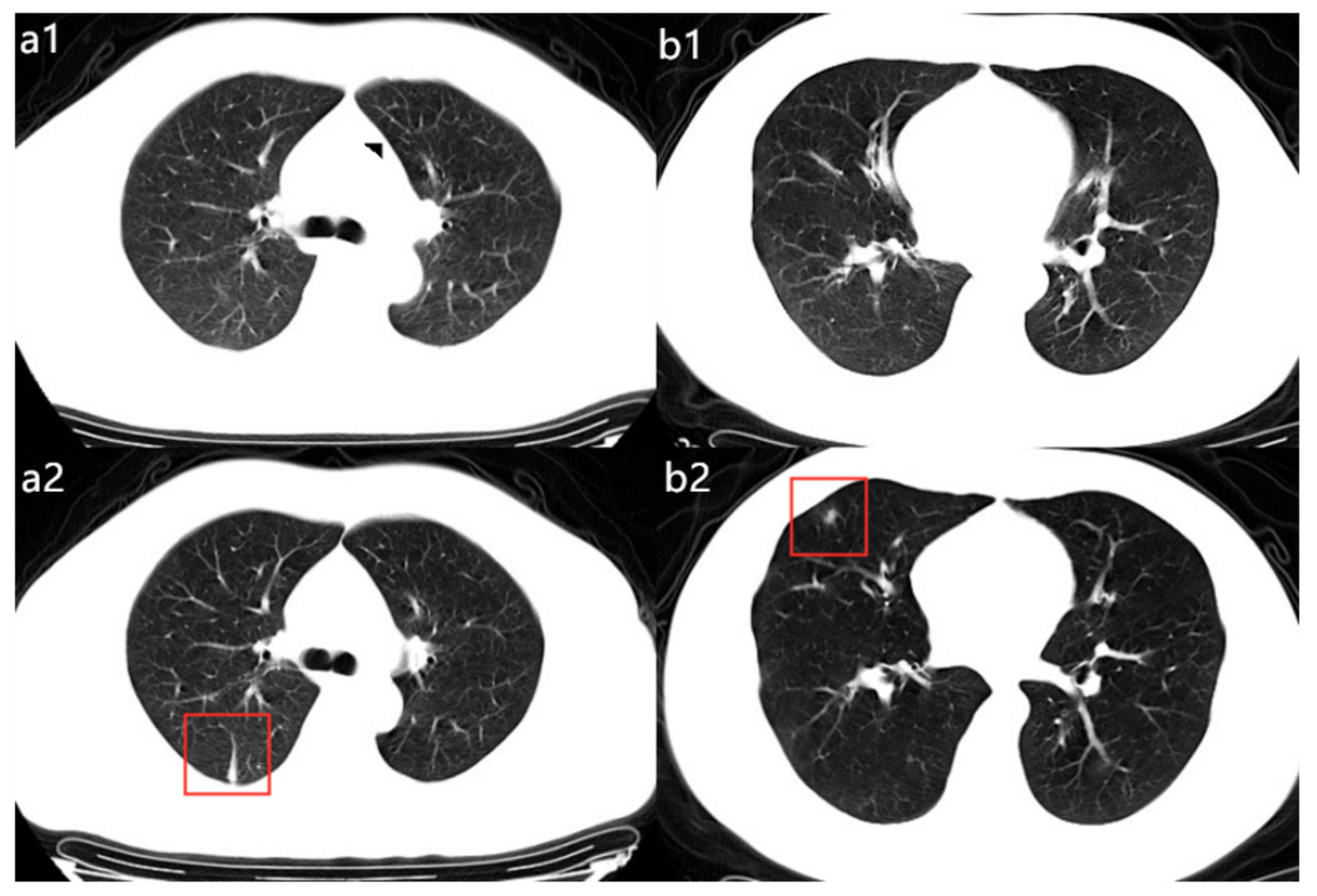

Figure 3

Examples of patients with admitting diagnosis as non-pneumonia in Group 2. (a1-a2) a 45-year-old man with confirmed with non-pneumonia COVID-19 and had hospitalization days of 16. Patients had fever at onset of disease, but normal CT images at the beginning of the admission (a1), at 4th day on admission, the follow-up CT images demonstrated inflammatory appearance as linear shadowing (a2). (b1-b2) a 31year-old man diagnosed as non-pneumonia with COVID-19 who had cough at onset but normal CT images (b1). Total hospitalization time was 18 days. After 4 days admission, an irregular consolidate nodule can be seen in the right middle lobe from the follow-up CT images (b2). 


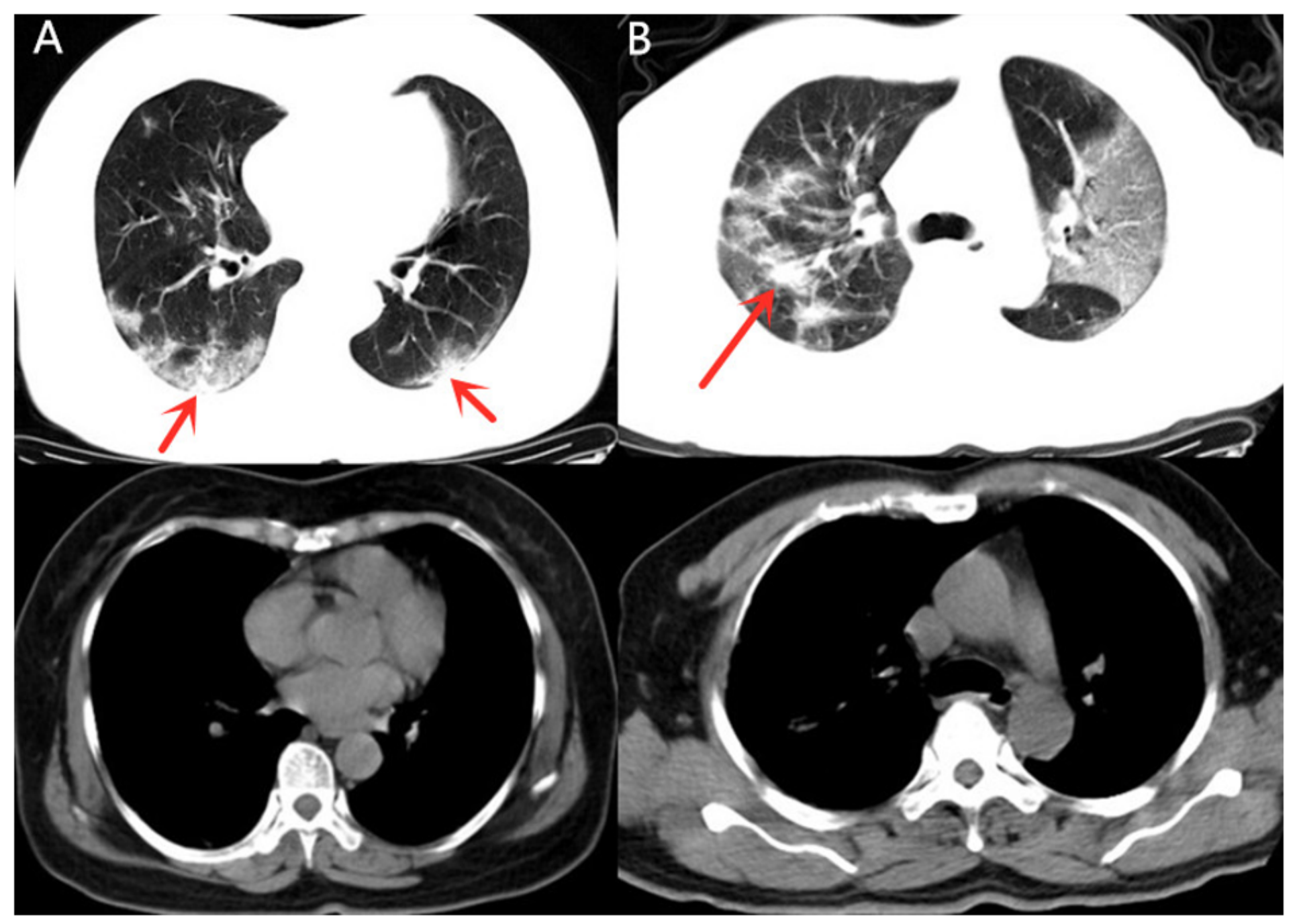

Figure 4

Example of patients with CT demonstrated as GGO>consolidation in Group 1. A. 65-year-old female with confirmed COVID-19 pneumonia in Group 1 who had hospitalization time of 12 days. CT images demonstrated multiple mixed GGO and consolidation lesions with bilateral distribution, the consolidation component (arrow) was apparently less than GGO. B. 53-year-old man in Group 1 with 12 admission days. Multiple mixed GGO and consolidation lesions with bilateral distribution were seen in his CT images, at the same time. The range of GGO components was apparently more than consolidation (arrow). 


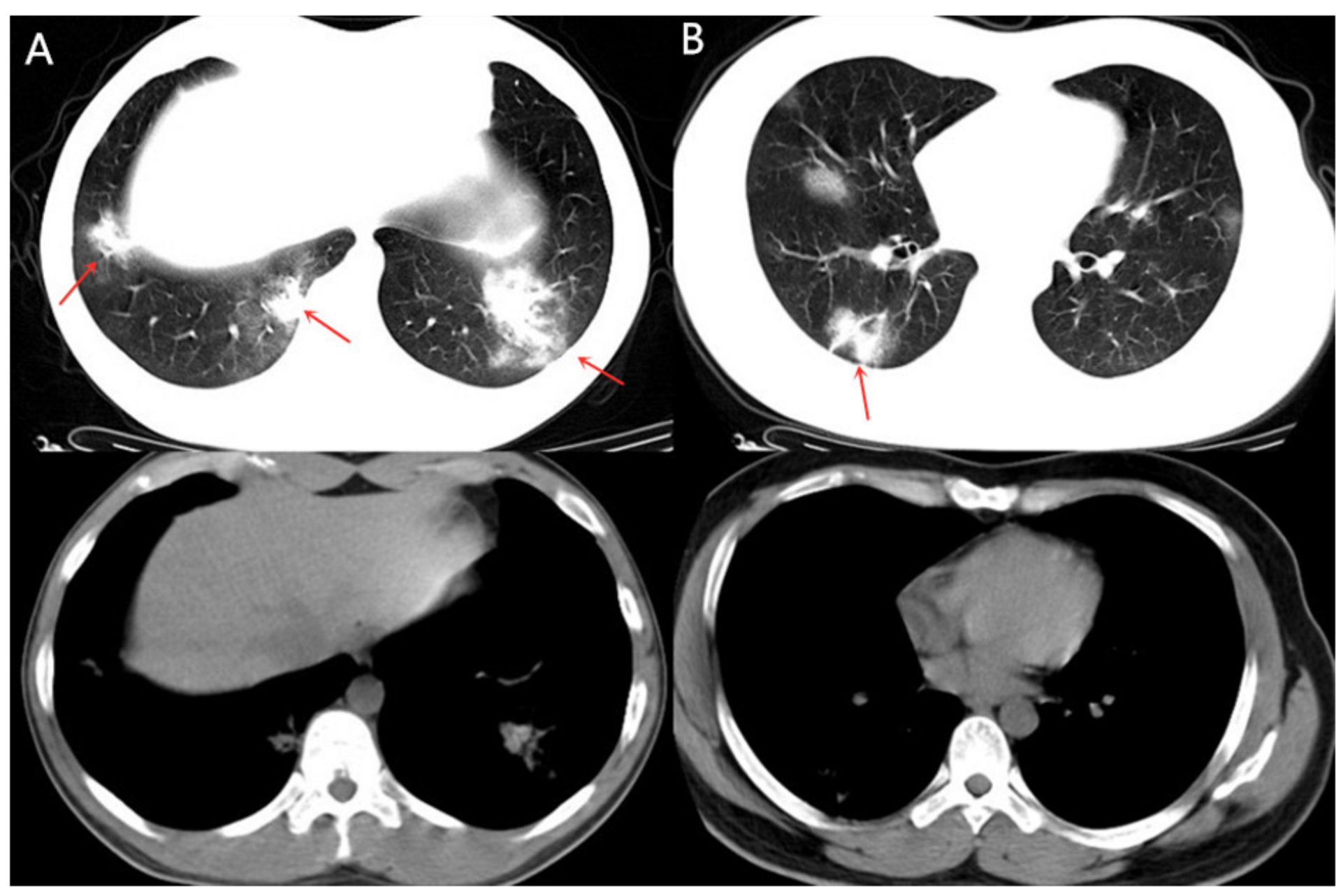

Figure 5

Example of patients with CT demonstrated as consolidation > GGO component in Group 2. A. 29-year-old female confirmed with COVID-19 pneumonia in Group 2 who had hospitalization days of 19 days. CT images demonstrated multiple lesions with mixed density which were predominantly solid components (arrows). B. 28-year-old male in Group 2 with hospitalization days of 19 days. CT images also demonstrated multiple mixed density lesions with predominantly solid components (arrows). 